\title{
sciendo
}

Current Issues in Pharmacy and Medical Sciences

Formerly ANNALES UNIVERSITATIS MARIAE CURIE-SKIODOWSKA, SECTIO DDD, PHARMACIA

\section{Nano chitosan encapsulation of Cymbopogon citratus leaf extract promotes ROS induction leading to apoptosis in human squamous cells (HSC-3)}

\author{
Sasqia FaAdillah Andikoputri ${ }^{1}$, Komariah Komariah ${ }^{2 *}$, \\ M. Orliando Roeslan ${ }^{3}$, Dewi Ranggaini ${ }^{4}$, Del Afriadi Bustami ${ }^{2}$
}

\begin{abstract}
${ }^{1}$ Dentristry Student of Faculty of Denstistry Trisakti University, West Jakarta, Indonesia
${ }^{2}$ Department of Histology, Faculty of Denstistry Trisakti University, West Jakarta, Indonesia

${ }^{3}$ Department of Oral Biology, Faculty of Denstistry Trisakti University, West Jakarta, Indonesia

${ }^{4}$ Department of Physiology, Faculty of Denstistry Trisakti University, West Jakarta, Indonesia
\end{abstract}

\section{ARTICLE INFO}

Received 03 March 2021

Accepted 20 July 2021

\section{Keywords:}

reactive oxygen species, encapsulation,

nano chitosan,

C. citratus leaf extract,

HSC-3.

\begin{abstract}
World-wide, Indonesia is ranked $17^{\text {th }}$ in oral cancers, with deaths reaching 2.326 cases. Of the oral cancers, $90 \%$ are squamous cell carcinoma (HSC-3). Unfortunately, conventional cancer therapy still has many ill side effects. Therefore, pharmacologists have looked for natural ingredients to prevent the growth of oral cancer cells. One source is Cymbopogon citratus leaf. Research shows that the active compound of C. citratus leaf is a chemopreventive, doing so by increasing the production of re-active oxygen species (ROS) to induce apoptosis in cancer cells. The active compound of $C$. citratus leaf has low stability and solubility, so it is necessary to use an encapsulation matrix such as chitosan, and modify it into smaller particles to increase its effectiveness.

Purpose is determining the effect of nano chitosan encapsulation of $C$. citratus leaf ethanol extract (NCECC) on the reactive oxygen species of HSC-3 tongue cancer cells. This study is divided into ten groups - without treatment, doxorubicin (positive control), hydrogen peroxide, nano chitosan and C. citratus leaf extract groups, and five groups of NCECC treatment - concentrations of $100 \%, 75 \%, 50 \%, 25 \%$, and $12.5 \%$, respectively. The $100 \%$ NCECC group showed the highest ROS concentration ( $\mathrm{p}<0.05)$, compared to $75 \%, 50 \%$, $25 \%, 12.5 \%$ NCECC groups, and the 100\% NCECC was higher than the positive control group. NCECC is effective in inducing oxidative stress on HSC-3 through increased production of ROS. Moreover, the higher the encapsulation concentration given, the greater the increase in ROS production.
\end{abstract}

\section{INTRODUCTION}

The International Agency for Research on Cancer put Indonesia in $17^{\text {th }}$ rank with 5.078 cases and 2.326 deaths [1]. Oral cancer cells commonly found are oral squamous cell carcinoma (OSCC) with a percentage of $90 \%$. Oral cancer develops from stratified squamous epithelium which can found on the lips, $2 / 3$ of the anterior part of the tongue, salivary glands, gingiva, the floor of the oral cavity and palatal, with the predilection most often found on the lateral tongue by $75 \%$ and $25 \%$ on the tongue base [2] using the topographic definition used by the Union Internationale Contre le Cancer (UICC).

\footnotetext{
* Corresponding author

e-mail: komariah@trisakti.ac.id
}

Standard therapy for tongue cancer includes surgery, radiotherapy and chemo- therapy. However, conventional cancer therapy has ill side effects, so many studies focus on compounds from natural ingredients safe for the body. They can act as chemo-preventives.

C. citratus or lemongrass, can induce apoptosis through increased reactive oxygen species (ROS). ROS are free radicals produced by mitochondria and can control cell proliferation by inducing cells to apoptosis [3]. They are generated either endogenously or exogenously. Endogenous factors including mitochondria, peroxisomes and endoplasmic reticulum and exogenous factors are pollution, alcohol, smoking and radiation [3]. In addition, ROS can be either radical and non-radical. Radical ROS such as superoxide, 
hydroxyl, alkoxy radicals and peroxyl radicals are highly reactive. The non-radicals include hydrogen peroxide and ozone and are moderately reactive [4].

C. citratus stem is widely used as a spice and traditional medicine because it has antitumor, antiviral, antifungal and antibacterial activities. The leaf of $C$. citratus has active compounds such as alkaloids, saponins, tannins, flavonoids, phenols and steroids with a higher content than the stems. However, C. citratus leaf is still a waste that cannot be widely utilized [5].

Active compounds from natural ingredients have limited bioavailability and solubility. This affects absorption in the body, and the limitation can be controlled using encapsulation by means of polymers, such as chitosan. Chitosan is a natural liner polysaccharide obtained from deacetylation of chitin derived from Xylotruphes gideon [6]. Physical modification of the nano chitosan encapsulation of $C$. citratus leaf extracts (NCECC) into nanoparticles makes it more reactive and easily absorbed by the body. This study aimed to determine the effect of NCECC on the production of ROS by the percentage of green intensity fluorescence HSC-3.

\section{MATERIAL AND METHODS}

Lemongrass leaf was harvested from Parung, Bogor, Indonesia. Chitosan was attained from the demineralization, deproteinization and deacetylation of $X$. gideon obtained from a coconut plantation in the Dramaga area, Bogor, Indonesia. $C$. citratus leaf was extracted by maceration via $70 \%$ ethanol (Merck) using the Buchi R-215 Rotavapor System (Germany). HSC-3 cells were derived from the integrated laboratory of Yarsi University, Indonesia. Probe 2',7'-Dichlorodihydrofluorescein Diacetate (H2DCFDA) and 4',6- diamidino-2-phenylindole (DAPI) were obtained from Santa Cruz Biotechnology (Dallas, USA).

\section{Production of Nano Chitosan Encapsulation of $C$. citratus}

\section{Lemongrass Leaf Extract}

To create the lemongrass extracts, 300 grams simplicia lemongrass leaf was soaked in $70 \%$ ethanol $(1: 10)$ for $3 \times$ 24 hours at room temperature, filtered using Whatman filter paper and evaporated at a temperature of $50-60{ }^{\circ} \mathrm{C}$. Various concentrations were generated $(100 \%, 75 \%, 50 \%, 25 \%$, $12.5 \%$ and $10 \%$ ). To encapsulate this extract, 0.5 grams of chitosan $X$. gideon was dissolved with $1 \%$ acetic acid (Merck). Subsequently, $2 \mathrm{~mL}$ of lemongrass extract and $100 \mathrm{~mL}$ of distilled water were added. The mixture was then stirred with a magnetic stirrer (IKA ${ }^{\mathrm{TM}} \mathrm{RH}$ basic 2 , Germany) (2500 rpm) for two hours. Following this, $40 \mathrm{~mL}$ of tripolyphosphate $0.1 \%$ (Merck) was placed drop-wise into the mixture and then it was stirred for one hour, and $0.1 \mathrm{~mL}$ of tween $80(0.1 \%)$ was added. The mixture was subsequently stirred once more for 30 minutes. the particle size was tested using the Particle Size Analyzer (Malvern Zetasizer nano series, UK).

\section{HSC-3 ROS Test}

HSC-3 cells were grown in cell culture DMEM at $37^{\circ} \mathrm{C}$ and $5 \% \mathrm{CO}_{2}$. The negative group of HSC-3 cells was alone without treatment $(\mathrm{K} 0)$; the positive control group was given doxorubicin $3 \mu \mathrm{M}(\mathrm{K} 1)$. Three other groups were the C. citratus leaf extract $10 \%(\mathrm{~K} 2)$, nano chitosan $0.5 \%(\mathrm{~K} 3)$ and hydrogen peroxide $0.1 \%(\mathrm{~K} 4)$. The treatment group was given NCECC with a concentration of $100 \%(\mathrm{P} 1)(\mathrm{v} / \mathrm{v}), 75 \%$ (P2), 50\% (P3), 25\% (P4), and 12.5\% (P5), and incubated for three hours, then washed with $1 \mathrm{X}$ PBS. Subsequently, one $\mathrm{mL}$ of H2DCF-DA probe $(10 \mu \mathrm{M})$ was added, and the mixture incubated for 30 minutes in the dark. The mixture was then washed with 1X PBS 2 twice and given $1 \mathrm{~mL}$ of DAPI $(300 \mu \mathrm{M})$ for three minutes. After this, the mixture was washed with $1 \mathrm{X}$ PBS three times. The green fluorescent cells were observed using Zeiss Z1 Inverted Fluorescence (Germany) and calculated independently by three people using Image J software. The percentage of cells with ROS production, namely, the cells with green fluorescence intensity, was divided by the total number of cells (green + blue fluorescence) and multiplied by 100 [7] we show that iCOUNT allows for novel insights into stem cell behaviour. Further, we used single cell RNA-sequencing (scRNA-seq).

\section{Data Analysis}

The data obtained is presented as mean \pm standard deviation (SD). The normality test was performed using the Shapiro-wilk test. If the results showed normal data $(p>0.05)$, one-way ANOVA was applied, if there was a significant difference result shown via one-way ANOVA $(p<0.05)$, then Post Hoc test was used. Data analysis was undertaken via SPSS version 2.3.

\section{RESULT AND DISCUSSION}

Cymbopogon citratus has several beneficial active compounds. Among these are alkaloids, flavonoids, tannins, steroids, triterpenoids and saponins. H2DCFDA is a probe used to detect ROS. The probe will penetrate the cell membrane and the esterase enzyme will convert H2DCFDA into a non-fluorescent component of H2DCF. In contrast, the presence of ROS in cells will convert H2DCF to fluorescent green $2^{\prime}, 7^{\prime}$ - dichlorofluorescein (DCF), the intensity of fluorescent green herein indicates the ROS level in the cell.

The NCECC particle distribution test results revealed that the nano-sized particles average is $161 \mathrm{~nm}$. NCECC has good applications and is gaining wider attention in pharmaceutical and biomedical research, with nanoparticles $<100$ $\mathrm{nm}$ in size improving biodistribution and site-specific drug delivery capabilities [8].

The K1 group showed significant differences $(p<0.05)$ from the K0, P4 and P5 groups, but the K1 group was not significantly different ( $p>0.05$ ) from the K2, K3, K4, P1, P2 and P3 groups. The intensity of green fluorescence in the $\mathrm{K} 1$ group was $48.34 \pm 0.96$. The $\mathrm{K} 0$ group that was not given treatment indicated green fluorescence of $32.51 \pm 6.25$, and was significantly different $(\mathrm{p}<0.05)$ from all groups, namely $\mathrm{K} 1, \mathrm{~K} 2, \mathrm{~K} 3, \mathrm{~K} 4, \mathrm{P} 1, \mathrm{P} 2, \mathrm{P} 3$, and P4 (1). 
The K2 and K3 groups demonstrated green fluorescence of $49.03 \pm 1.92$ and $49.72 \pm 1.17$, the difference being insignificant $(\mathrm{p}>0.05)$. Hence, the two groups have the same ability to increase the production of ROS. The group given the stressor resulted in a green fluorescence intensity of $45.85 \pm 1.46$. The K4 group could be experiencing oxidative stress as green fluorescent cells were evident (Figure 1).

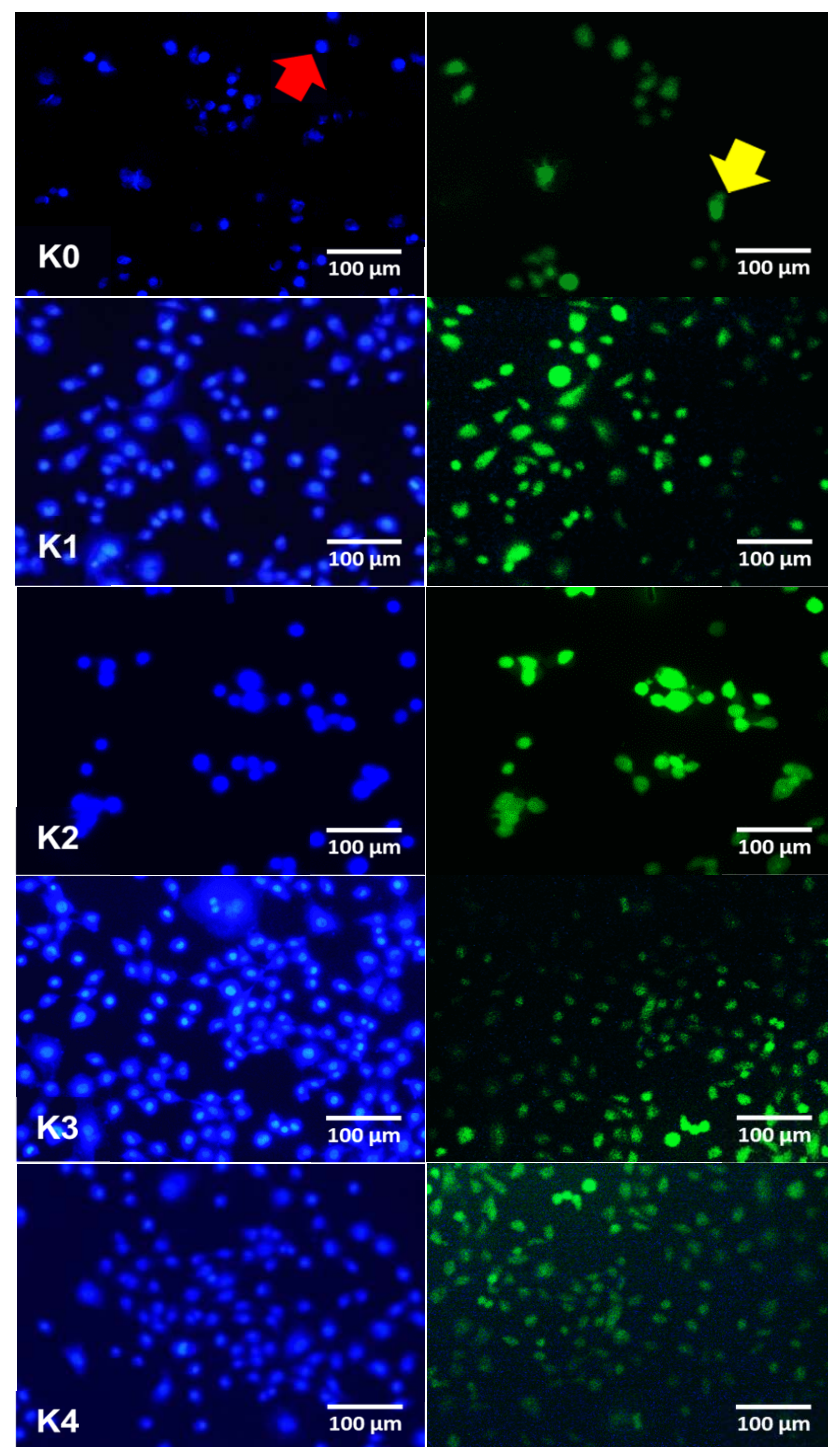

Figure 1. Green fluorescent cells (yellow arrow) and blue fluorescent cells (red arrow) in HSC-3. Green fluorescent cells representative images of these levels of ROS from the control group (K0), Doxorubicin (K1), C. citratus leaf extract (K2), nano chitosan (K3), and hydrogen peroxide (K4)

The NCECC treatment group revealed differences in green fluorescence. Group P1 $(51.15 \pm 0.26)$ showed more green fluorescence $(\mathrm{p}<0.05)$ compared to $\mathrm{P} 4$ and $\mathrm{P} 5$ groups (42.61 \pm 0.74 and $26.31 \pm 2.85$, respectively). Although the P2 and P3 groups were not significantly different $(p>0.05)$ from the P1 group, the degree of green fluorescence was lower than those in the $\mathrm{P} 1$ group, the experimental outcome being $48.38 \pm 0.82$ and $47.07 \pm 0.56$, respectively (Figure 2 ). The results of observing the green fluorescence in the groups given NCECC at different concentrations indicated an excellent synergy between the ethanol extract of $C$. citratus leaf and chitosan physically modified into nanoparticles. Here, the number of green fluorescent cells varied directly with increase of concentration of NCECC. The results of one-way ANOVA test are presented in Table 1.

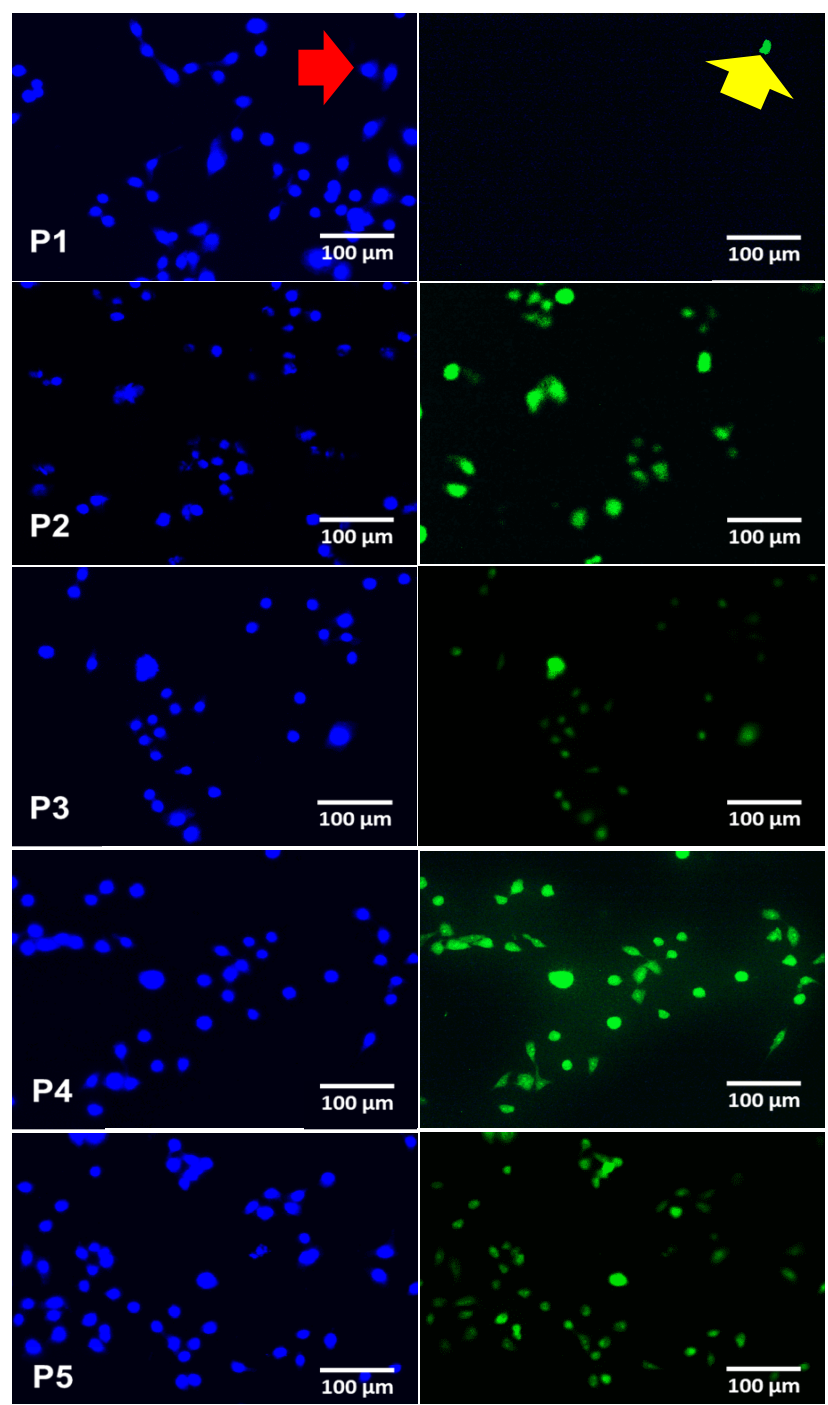

Figure 2. Green fluorescent cells representative images of these levels of ROS HSC-3 from treatment NCECC group 100\% (P1), group 75\% (P2), group 50\% (P3), group 25\% (P4), and group $12.5 \%(\mathrm{P} 5)$

Table 1. Mean of Green Fluorescent Cells HSC-3

\begin{tabular}{|c|c|c|c|}
\hline \multirow{2}{*}{ Group } & \multirow{2}{*}{$\mathrm{N}$} & Green Fluorescent Cells & \multirow{2}{*}{$\mathrm{p}$-value } \\
\hline & & $(\%)$ & \\
\hline KO & 3 & $32.51 \pm 6.25^{*}$ & \multirow{10}{*}{0.000} \\
\hline K1 & 3 & $48.34 \pm 0.96$ & \\
\hline K2 & 3 & $49.03 \pm 1.92$ & \\
\hline K3 & 3 & $49.72 \pm 1.17$ & \\
\hline K4 & 3 & $45.85 \pm 1.46$ & \\
\hline P1 & 3 & $51.15 \pm 0.26$ & \\
\hline P2 & 3 & $48.38 \pm 0.82$ & \\
\hline P3 & 3 & $47.07 \pm 0.56$ & \\
\hline P4 & 3 & $42.61 \pm 0.74$ & \\
\hline P5 & 3 & $26.31 \pm 2.85 *$ & \\
\hline
\end{tabular}

The increase in ROS number will induce cells to apoptosis through intrinsic and extrinsic pathways. The large 
amount of ROS production in cancer cells that is obtained from intrinsic (inside the cell from mitochondria) or extrinsic (environment) factors) generates mitochondria dysfunction. ROS increase will activate Akt/MAPK and bring about conformational changes in Bcl-2 and Bax, disrupting the mitochondrial membrane thereby inducing the release of Cytochrome-C, which, together with Apaf-1 and cytochrome-C forms 'apoptosomes' and activates caspase-9, which then excites an effector caspase, such as caspase-3 - causing cell death or apoptosis [9].

In cancer cells, ROS plays a role in the migration, proliferation and survival processes. An excess number of ROS in cancer cells can lead to cell death, so that cancer cells will increase antioxidants to maintain the balance of ROS production, by upregulating nuclear factor erythroid 2 - related factor 2 (NRF2), which will, in turn, activate Transient Receptor Potential Ankyrin 1 (TRPA1), through exciting ion channels in the in- flux of calcium ions into cells. The presence of calcium in cells will maintain a balance in ROS activity [10].

Nano chitosan can penetrate the space between cells through diffusion, and in- crease its effectiveness. Chitosan via signal activation of calcium $\left(\mathrm{Ca}^{2+}\right)$ [11] will activate ROS-producing enzymes, such as xanthine oxidase, lipooxygenase, cyclooxygenase and NADPH (dependent oxidase-2), so that the production of ROS in cancer cells increases [12]. This study is in line with research on cervical cancer cells (HeLa), breast cancer cells (MCF-7) and hepatocellular carcinoma (HCC) in experiencing apoptosis due to increased ROS after exposure to nano chitosan $[13,14]$.

The $C$. citratus extract group containing flavonoids and their derivatives will inhibit the reduced glutathione enzyme (GSH), resulting in an increase in ROS causing oxidative stress and mitochondrial dysfunction through the intrinsic apoptosis pathway [9]. In previous studies, giving C. citratus induced cell death of non-Hodgkin lymphoma (U-937) and Jurkat (E6-1) cells, through increased ROS [15].

The encapsulation of $C$. citratus leaf extract with chitosan provides a synergis- tic effect as a chemopreventive HSC-3, as shown by the induction of NCECC in in- creasing the production of ROS. The active compound in C. citratus leaf extract works as a chemopreventive and is delivered by nano chitosan directly to the cell membrane. Apart from the demonstrated anticancer properties, $C$. citratus can act as an antifungal [16] and also protect normal cells through conducting oxidative stress [17]. Specifically, the active compound in $C$. citratus leaf extract can inhibit reduced glutathione (GSH) and activate intracellular calcium $\left(\mathrm{Ca}^{2+}\right)$ signals that initiate ROS-producing enzymes. This theory is reinforced by direct effect of increase green fluorescence with enhanced NCECC concentration. Thus, we believe that the use of natural ingredients can serve as alternatives to current cancer therapy - doing this with reduced side effects.

\section{CONCLUSION}

NCECC effectively induces apoptosis in HSC-3 through increased ROS pro- duction. This was indicated by the intensity of green fluorescence. The best NCECC concentration in increasing ROS was at $100 \%$.

\section{ACKNOWLEDGEMENT}

This study was supported by the Faculty of Dentistry, Trisakti University

\section{ORCID iDs}

Komariah Komariah (Dhttps://orcid.org/0000-0001-8945-716X

\section{REFERENCES}

1. World Health Organization (WHO). Indonesia Fact Sheets. International Agency for Research on Cancer; 2012.

2. de Camargo Cancela M, Voti L, Guerra-Yi M, Chapuis F, Mazuir M, Curado MP. Oral cavity cancer in developed and in developing countries: Population-based incidence. J Sci Spec Head Neck. 2009. https://doi.org/10.1002/hed.21193

3. Kardeh S, Ashkani-Esfahani S, Alizadeh AM. Paradoxical action of reactive oxygen species in creation and therapy of cancer. Eur $J$ Pharmacol. 2014;735:150-68.

4. Phaniendra A, Jestadi DB, Periyasamy L. Free radicals: properties, sources, targets, and their implication in various diseases. Ind J Clin Biochem. 2015;30(1):11-26.

5. Oladeji OS, Adelowo FE, Ayodele DT, Odelade KA. Phytochemistry and pharmacological activities of Cymbopogon citratus: A review. Sci Af. 2019;6:e00137.

6. Komariah A, A Tatara R, A Bustami D. Efficacy of Rhinoceros Beetle (Xylotrupes gideon) nano chitosan and calcium mouthwash in reducing quantity oral cavity bacteria among elementary school age children. Int J Adv Biol Biom Res. 2017;05(01):41-5.

7. Denoth-Lippuner A, Jaeger BN, Liang T, Chie SE, Royall N, Kruse M, et al. Visualization of individual cell division history in complex tissues. bioRxiv: https://doi.org/10.1101/2020.08.26.266171

8. Rizeq BR, Younes NN, Rasool K, Nasrallah GK. Synthesis, bioapplications, and toxicity evaluation of chitosan-based nanoparticles. IJMS. 2019;20(22):5776.

9. Aggarwal V, Tuli H, Varol A, Thakral F, Yerer M, Sak K, et al. Role of reactive oxygen species in cancer progression: Molecular mechanisms and recent advancements. Biomolecules. 2019;9(11):735.

10. Reczek CR, Chandel NS. ROS promotes cancer cell survival through calcium signaling. Cancer Cell. 2018;33(6):949-51.

11. Ivanova DG, Yaneva ZL. Antioxidant properties and redoxmodulating activity of chitosan and its derivatives: Biomaterials with application in cancer therapy. BioResearch Open Access. 2020;9. https://doi.org/10.1089/biores.2019.0028

12. Hernández-Espinosa DR, Massieu L, Montiel T, Morán J. Role of NADPH oxidase-2 in the progression of the inflammatory response secondary to striatum excitotoxic damage. J Neuroinflammation. 2019;16(1):91.

13. Martinez-Perez C, Ward C, Cook G, Mullen P, McPhail D, Harrison DJ, et al. Novel flavonoids as anti-cancer agents: mechanisms of action and promise for their potential application in breast cancer. Biochem Soc Trans. 2014;42(4):1017-23.

14. Jiang Y, Yu X, Su C, Zhao L, Shi Y. Chitosan nanoparticles induced the antitumor effect in hepatocellular carcinoma cells by regulating ROS-mediated mitochondrial damage and endoplasmic reticulum stress. Artif Cells Nanomed Biotechnol. 2019;47(1):747-56.

15. Philion C, Ma D, Ruvinov I, Mansour F, Pignanelli C, Noel M, et al. Cymbopogon citratus and Camellia sinensis extracts selectively induce apoptosis in cancer cells and reduce growth of lymphoma xenografts in vivo. Oncotarget. 2017;8(67):110756-73.

16. Tofiño-Rivera AP, Castro-Amaris G, Casierra-Posada F. Effectiveness of cymbopogon citratus oil encapsulated in chitosan on colletotrichum gloeosporioides isolated from capsicum annuum. Molecules. 2020;25(19):4447.

17. Madi YF, Choucry MA, El-Marasy SA, Meselhy MR, El-Kashoury E-SA. UPLC-Orbitrap HRMS metabolic profiling of Cymbopogon citratus cultivated in Egypt; neuroprotective effect against AlCl3induced neurotoxicity in rats. J Ethnopharmacol. 2020;259:112930. 